\title{
Rejected landscapes/recycled landscapes: waste disposal and recycling sites
}

\begin{abstract}
This article wants to show the landscape changes in the presence of waste, some touchable reality that invades the territory in many different ways in terms of time and space. Firstly, the issue of garbage is faced following its inevitable accumulation that designs our new and unexpected landscapes. Secondly, the focus will be on how waste can be turned into a place. So, how through a list of projects for more or less controlled recovery altered areas, the present territorial dimension is inexorably besieged by garbage and consequently how it is exposed to a substantial environmental, cultural, economic and political alteration. Consequently a sort of 'indicative atlas' - where some interesting and reference recovery plans are illustrated-will be shaped. This perspective shows the present conditions and the effective distribution of plants for waste disposal and collection on the European territory in general, and more particularly in Italy: here the study becomes more detailed and a territorial section in Italy, Lombardy, is going to be analyzed. The territorial morphology and the inevitable environmental transformations are also taken into consideration. So, through a study of the present territorial conceptual status, indicative and synthetic models shape up from possible and potential scenarios of areas that are or will be altered in the future. The study of these areas make up a unique path to observe and evaluate the modern urban structure, where presently it is necessary to have a correct, definite location, leading to territorial changes in different ways. Furthermore, this research can contribute to give the right measure of what is at stake that is different territorial status and other perspectives.
\end{abstract}

Volume 3 Issue I - 2017

\section{Silvia Dalzero}

Department of Civil Engineering, University of Venice, Italy

Correspondence: Silvia dalzero, Department of Civil Engineering, University of Venice, Italy, Email silviadal@virgilio.it

Received: April 17, 2017 | Published: July 17, 2017

\section{What we call progress}

The problem of collection and disposal of waste dates back in history but has become a crucial issue in relatively recent times, as far as quantity to recuperate, recovery of resources to deal with, novelty and variety of materials to destroy and disposal techniques at hand are concerned. Recalling what Paul Valery wrote in Il mio Faust: "The problem of waste basically comes from its material nature. Waste occupies space, it has volume and so it suffocates people besieging from close up". ${ }^{1}$ Modern populations have destroyed cities, nature, landscapes, souls, the sense of inviolable and sacred, tradition, art, reversing all this in the obese paroxysm of consumption and waste, in overflowing garbage disseminated everywhere. Properly this storm that transforms the past into a heap of debris, says Walter Benjamin, is "what we call progress". ${ }^{2}$ Besides now the waste makes up a world apart, a complex and symmetric universe made of goods: behind the mirror, this world of consumerism reflects itself and becomes conscious of it. Waste is the 'dark side' of a single reality, which indissolubly associates resource and waste. In effect, every time we throw away an object, by choice or obligation, we produce waste. We find waste everywhere; a mountain of waste which we have to absolutely get rid of and which hangs over our head. But how? The solutions adapted to eliminate waste are simply means of taking them away from our senses. In particular, from our sight and from our sense of smell. So, waste is abandoned in external landfills; consigned to the catharsis of fire or left to recycling systems. Consequently we need space: an empty space in order to store everything we no longer want to see. The fact is that disposal plants or waste treatments continue to be necessary, and locating them properly somewhere will be necessary. The question now remains, how and where? In principle, the process of discharge is so divided: it is linked to the type of refusal, to materials by which it is composed and to treatment plants and disposal on the ground. Therefore, every country uses different techniques at different percentages for waste disposal. Generally, more countries use storage in dumps or incineration plants (in 2009 in Europe there were 358 incineration plants in eighteen nations. In some situations, such plants have long been included in urban contexts, such as Brescia, Vienna, Paris, Copenhagen).

\section{The destiny of 'refuse' in an impure society}

Yes! Garbage and degradation have now become "places" and over this another reality has swept over and proliferated. There is a rejection of people, things and objects, pitiless and deliberately thrown out and poured randomly at the margins of existence, in dark inaccessible corners of infinite suburbs and outskirts of the world, in the new fields. Therefore, the new slums have become waste dumps and illegal rubbish of humanity by which we are consciously or unconsciously surrounded and from which we keep ourselves at proper distance. This determines a reality that is just as present as it is hidden. Waste, in effect, is in the foreground as well as in background, independent and at the same time connected to the city context. However, waste cannot be erased... We know quite clearly that since ever cities sat on their own waste that gradually grew all around; progressively waste started being pushed away from its origin. As a matter of fact, waste is transported far from the city limits, where discharged substances and toxic amounts are exported, quite often to Third World countries.

Waste is usually abandoned in areas where people with no power live, where rights on land are weak and there are no controls. We can observe the strong attitude towards pushing away at different levels; for example let's consider the houses where there are cellars or garages where we can pile up what no longer has a value for us. 
Let's just consider the residential suburbs where heaps of material that is no longer useful are, or garbage cans found at the borders of the neighborhood and finally let's observe where the public dumps or the polluting industries are found, in the limits of the confining cities. After all, people are not aware of the enormous proportions of the problem but it is evident in the present daily life that everything is transformed in hazardous waste, in particular, the electronic waste flow abundantly towards Third World countries as the illegal dumps, named dumps-cities. This and much more exists. In opposition to these devastated conditions by imperious presence of waste, in some cases garbage has become, instead, a source of social emancipation, for example: "Masdar city, the urban plan by Norman Forster's \& Partners" will be a city free of from polluting emissions, there won't be any waste storage because waste will be $99 \%$ recycled while the remaining $1 \%$ will end up in the appropriate compost plants and incinerator.

\section{Prospective and contemporary approaches bringing back a sense of place}

According to Zygmunt Bauman, waste always tends to go towards a "liquid state", ${ }^{3}$ that is to say, waste does not conserve its form for a long time and tends to transform itself into something else, it overflows, it spreads and drips non -stop. Under the push of globalization, the planet is becoming a gigantic waste global dump with an enormous quantity and variety of slag. After all, despite our reluctance regarding this, we are essentially what we are throwing away and we can actually say "we refuse, therefore we are", as a modern variant of the famous Cartesian phrase cogito, ergo sum.

Then, waste brings to mind daily negative images; however, there are new legal architectural languages for management and waste disposal. Thermo plants and controlled wasted dumps are an example. They create new architectural scenarios, landscapes which are always closer and closer to urban centers consequently, sooner or later, we have to learn to live with them. In particular, the controlled disposal dumps remain active for many years and as in all containers, once their capacity is full, they can be closed and become transformable areas, therefore an opportunity for planning. Regarding this, it is worth mentioning the well-known Fresh Kills in Staten Island, the largest waste dump in the world. In this case, as in others, rubbish is considered a source of energy as it happens in some urban waste dumps - from which methane gas can be extracted-or the incinerators, with their energy recovery. But waste dumps, incinerators have always been considered dirty places, hostile to relegate at great distance from inhabited centers and only in a few cases they have been located near the urban centers and become an occasion for the city. As a matter of fact, today there is evidence of most cases of landscape transformation altered by waste storage, are equipped with green areas. Reasonably a project in urban and environmental scale cannot be removed from the structural dynamics in which this is subject to and cannot be measured therefore with the different context of intervention without taking into consideration the constant relation between conservation/ recovery/ transformation. Today, many architects, city planners, and experts try to find new uses of urban centers in decadence or other abandoned industrial areas or sites subject to waste disposal and storage; therefore mines, caves or waste dumps can be considered primary resources or renewable earth. The waste disposal and collection activity create worn out lands: they can destroy the soil above, the vegetation, leave wells or holes, cause subsidence, contaminate the soil with salts, heaps of rubble, waste, acid and slime; therefore the recycling of these areas is tied to the environmental issues much more than the aesthetic features.

\section{Cartographic study}

The overall investigation starts particularly from the condition of Italy through the current distribution of plants for disposal and collected waste uses. The uniform distribution throughout the country is evident. Actually, every year in Italy more than 30.000.000ton of municipal waste are produced, managed by the municipalities, whose disposal is due to multiple issues: environmental, political, economic, and social ones. Firstly, it is important to know their location, state of reclaim, activity degree or their nature so a synergy of different skills and specific planning responses to every territorial condition is imposed. Furthermore, one thing on which we must reflect upon, comparing the collected data, is that large portions of territory are degraded by the phenomenon of landfills and it is clear that the regions primarily interested are: Puglia, Veneto and Lombardy. For this reason, the research continues with a detailed study about a section which is particularly subject to this phenomenon, namely: the Lombardy region, and the highway area from Milan to Brescia where most Lombardy plants are located. So, this study wants to survey the state of the fact, the environmental impact, the urban 'sense' that sometimes these things take on outlining new metropolitan scenarios.

\section{Places subject to the presence of garbage}

In order to evaluate how this peculiar urban issue interacts with the urban and territorial system, the plants in the province of Brescia have been studied individually to put together an outline of the real or probable landscape scenarios that have been altered by waste. These territories seek for a new architectural redefinition, with the aim of being integrated into the urban contemporary system, as they almost always appear as inaccessible or closed systems. Therefore, from the real exploration of these areas, particular urban scenes clearly emerge. Their variety and articulation comes from a simple declination of three types of plants: incinerators, dumps and waste treatment plants.

Anyway, common issues to each of these realities are separation, expulsion and isolation which these places have in the contemporary urban system. At the same time we will see the attempts to reduce or mitigate the environmental impact that arises being inadequate, defective and incomplete. As a matter of fact it is clear that the city of Brescia has plenty of opportunities to locate plants for waste storage primarily because it is characterized by many caves. The city has also an extended and well-constructed road infrastructural system that is well connected to the surrounding urban area which strategically connects the wasted disposal areas. In this way, the streets and roads may clearly become technical spaces of connection and facilities.

\section{Conclusion}

In order to open a window on the present context, to critically, clearly and synthetically illustrate and interpret present or future potentials, to give territorial scenarios that take form in these areas, common factors have been investigated and searched for each of these multiple realities. The issue was explained through various scenarios because the experiences registered are many. In this case, we don't want to define just one imperative solution or even find the 
beginning of possible regulations. Instead, what it has to be done is beginning a dialogue among the players involved - political, technical, management or environmental authorities - and define in particular possible territorial relations between plants from one side (even past, present or future ones) and plants included the urban system itself from the other side. These numerous spaces can become very active structures in the urban context, they can connect to other urban spaces, whether they are constructed or not, they can be involved in alternative uses and they can be a reference point by taking on an identity, a role etc. Waste plants are a geographic, exploitable capital they are important components in a project of reconfiguration and requalification of territories. The purpose of this research is to give a detailed study of the existing condition and defines ideally strategic maps, of what can become a project of recovery in an 'ecological context' able to give sense to the worldwide popular statement 'ecologically sustainable' society. Plants to be then designed for the recovery of spaces that guarantee not only safety, but health and functional performance actively, coherently and in an organic way to better the urban territory as a whole.

\section{Acknowledgments}

None.

Funding

None.

\section{Conflicts of interest}

The authors declare there is no conflict of interests.

\section{References}

1. Paul Valéry. My faust draft. 1946.

2. Zeitschrift fur Sozialforschung. The work of art in the age of its technical reproducibility Walter Benjamin. L'opera d'art nell'epoca della sua riproducibilità tecnica. 1936.

3. Zygmunt Bauman. Modus vivendi. Inferno and utopia the liquid world. 2007. 31 p. 